\title{
LIFE CYCLE COST ANALYSIS: ACTUAL PROBLEM IN INDUSTRIAL MANAGEMENT
}

\author{
David Elmakis, Anatoly Lisnianski \\ Planning, Development \& Technology Division \\ The Israel Electric Corporation, Ltd \\ Str. Nativ haor 1, New Office Building, Haifa, 31000, Israel \\ Received 3 October 2005; accepted 7 December 2006
}

\begin{abstract}
The reliability associated costs are the main part of total life cycle cost for any repairable system. The paper presents the history of life cycle cost analysis, its principles and applicable standards. It analyzes the reasons behind the contradiction between the great theoretical achievements and their relatively rare applications in practice. It was shown that incorrect management is the main reason. Measures for management improvement were suggested.
\end{abstract}

Keywords: Life cycle cost, management, education.

\section{Introduction}

Reliability is an important factor in the management, planning and design of any engineering product. Today, in the global economy and due to various market pressures, the procurement decisions for many products are not based only on initial purchasing costs, but on their total life cycle costs [1]. Any important decision such as reliability allocation, spare parts storage, operation modes etc. is based on total life cycle cost. Total life cycle cost analysis should include all types of costs associated with system life cycle. The main part of these costs for repairable systems is operation and maintenance cost. In order to repair a system we must buy corresponding spare parts, so we must pay money for spare parts purchasing. We also must pay for spare parts storage and pay to the repair team that works in order to repair a system. In additional there are financial losses, when a system interrupts its work because of failure and so on. All these costs together are significantly greater than a system purchasing cost.
In order to perform an effective life cycle cost analysis, efforts from specialists in many areas (including engineering design, finance and accounting, estimating, statistical analysis, reliability and maintainability engineering, logistics and contracting) should be united in the framework of single team. Creation and correct managing of such team is one of the main problems of practical reliability management.

Unfortunately, in many practical cases this problem is incorrectly solved or not solved at all. Often, managers don't even recognize the problem existence. As a result, we have a significant contradiction between the great theoretical achievements of reliability theory and their relatively rare applications in practice.

The paper presents the history of Life Cycle Cost analysis, its principles and applicable standards, analyzes the reasons behind the failures in reliability management and suggests measures for the improvement. Significant amount of money may be saved as a result of correct reliability management. 


\section{Basic Life Cycle Cost Concepts}

Life Cycle Cost (LCC) of a system (product) is the total cost of acquiring and utilizing a system over its entire life span. LCC includes all costs incurred from the point at which the decision is made to acquire a system, through operational life, to eventual disposal of the system. So, in other words, LCC is the total cost of procurement and ownership. As it was shown in many studies, the ownership cost (logistics and operating cost) for repairable systems can vary from 10 to 100 times the procurement cost $[2,3]$. The history of life cycle costing began in the mid-1960s when a document entitled "Life Cycle Costing in Equipment Procurement" was published [4]. In 1974, Florida became the first U.S. state to formally adopt the concept of life cycle costing and in 1978, the USA Congress passed the National Energy Conservation Policy Act [1]. According to this act every new federal government building should be life cycle cost effective. From this time till now numerous works were published in this field. A variety of approaches were suggested in order to estimate the cost elements and provide inputs to the establishment of a life cycle cost model. The total life cycle cost model is thus composed of subsets of cost models which are then exercised during trade-off studies. These cost models range from simple informal engineering/cost relationships to complex mathematical statements derived from empirical data.

As it is known, total LCC are expressed in simple mathematical terms as sum of acquisition cost (AC) and system utilization cost:

$\mathrm{LCC}=\mathrm{AC}+\mathrm{SUC}$,

where: LCC - life cycle cost;

$\mathrm{AC}$ - acquisition cost;

SUC - system utilization cost.

Fig 1 identifies the more significant cost types and shows how LCC may be distributed in terms of major cost categories over a system life cycle.

In general, design \& development costs include materials, labor, administrative, overhead, handling and transportation.

Production cost includes all types of costs associated with system production.

Operational \& support cost includes a spares and replacements, equipment maintenance, inventory management, support equipment, personnel training, technical data/documentation, and logistics management. In addition, there are financial losses, when a system interrupts its work because of failure.

Disposal costs include all costs associated with deactivating and preparing the system for disposal through scarp or salvage programs. Disposal cost may be adjusted by the amount of value received when the disposal process is through salvage.

The major components of a repairable system life cycle are its operation and support phase and the associated operation \& support cost. LCC analysis provides a meaningful basis for evaluating alternatives regarding system acquisition and operation and support costs. Based on this analysis development and production goals can be established as well as an optimum required reliability level. Fig 2 illustrates the relationships between reliability and cost (MIL-STD338B). The top curve is the total life cycle cost and is the sum of the acquisition or investment and operation and support costs. The figure shows that in general more reliable system has lower support cost. At the same time, acquisition cost (both development and production) is increased to attain the improved reliability. The point where the amount of money (investment) spent on increasing reliability will result in exactly that same amount saved in support cost. This point represents the reliability for which total cost is minimum.

The implementation of an effective program based on

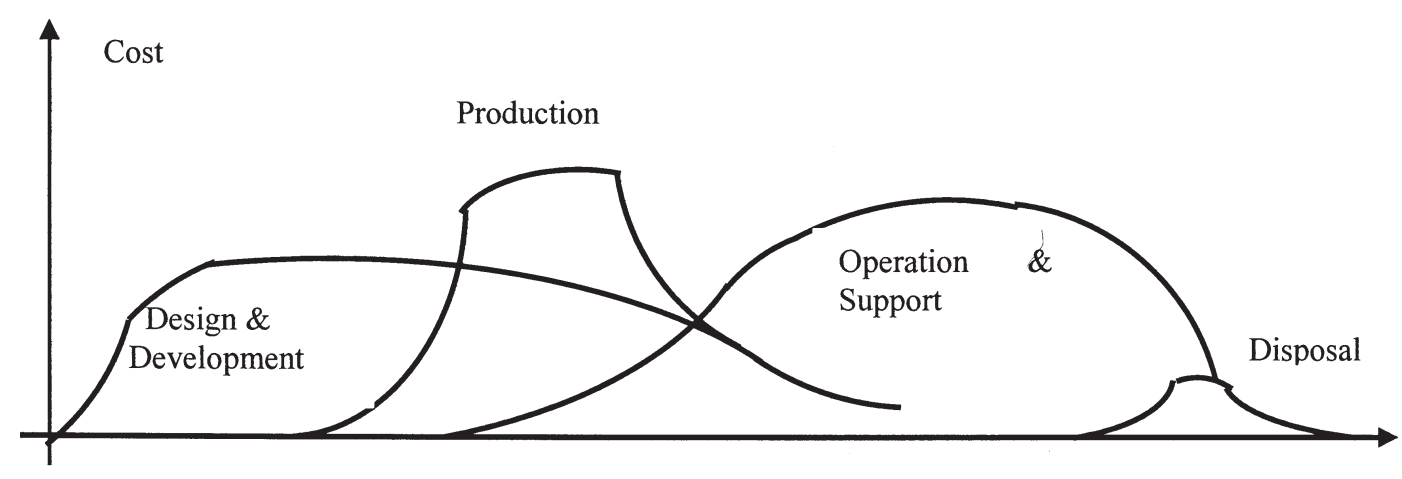

Fig 1. Different types of costs 


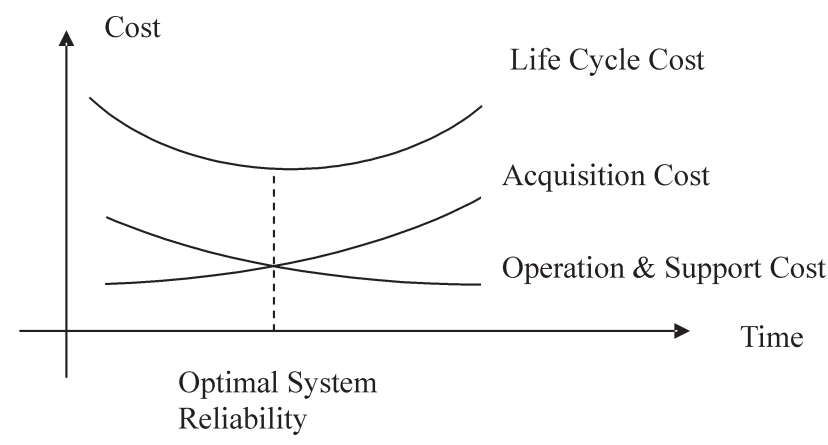

Fig 2. Life Cycle Cost as a function of the system reliability

proven LCC principles complete with mathematical models and supporting input cost data will provide early cost visibility and control, i.e., indicate the logistics and support cost consequences of early research, development and other subsequent acquisition decisions.

\section{Life Cycle Costing Activities, Corresponding Management and Required Manpower}

There are many known advantages of LCC approach such as making effective equipment replacement decisions, comparing the cost of competing projects and making a selection among the competing contractors etc. On other hand, to provide correct LCC analysis for real system is not a simple job. It requires very high professional skill of associated professionals, first of all because of the absence of general models recommended for LCC analysis in standards. Theoretically there are many methods ("a variety of approaches" as it is formulated in MILSTD), but for practice - it is nothing to use immediately. Because of this reason LCC analysis till now is bad-formalized problem and its solution is also expensive and time-consuming. Almost for any practical case it is required to provide additional research work.

To perform Life Cycle Cost Analysis the following steps should be executed as shown in fig 3. Usually step 2, where all involved costs should be estimated, requires most amounts of time and resources. To estimate correctly operation and support costs the variety of special models should be developed and analyzed. There are models for inventory (spare parts) management, complex reliability models that take into account all types of redundancy, different operation modes, different failure modes etc., models for estimation of losses because of system failures (for example, financial losses because interruption of power supply to consumers) and so on. Developing such models requires high professional skill from associated personnel.

In order to perform an effective life cycle cost analysis, the life cycle cost analyst must possess skills in many areas including engineering, finance and accounting, estimating, statistical analysis, reliability and maintainability engineering, logistics, and contracting. Of course, there cannot be a single professional - it should be a corresponding team which includes the following professionals: design engineers, reliability \& maintenance engineers, tooling engineers, planning engineers, test engineers, quality control engineers, manufacturing engineers. Therefore, in order to provide LCC analysis in practice, one has actual management problem: organize high-level research work, which involves different departments and is also expensive and time consuming. The corresponding team (or working group) should be composed of people who have specialties in various branches of engineering. Usually the team (or working group) performing life cycle cost analysis should be part of the logistics (or reliability department). The head of this group should have experience and corresponding background in areas such as probability theory, reliability engineering and quality control,

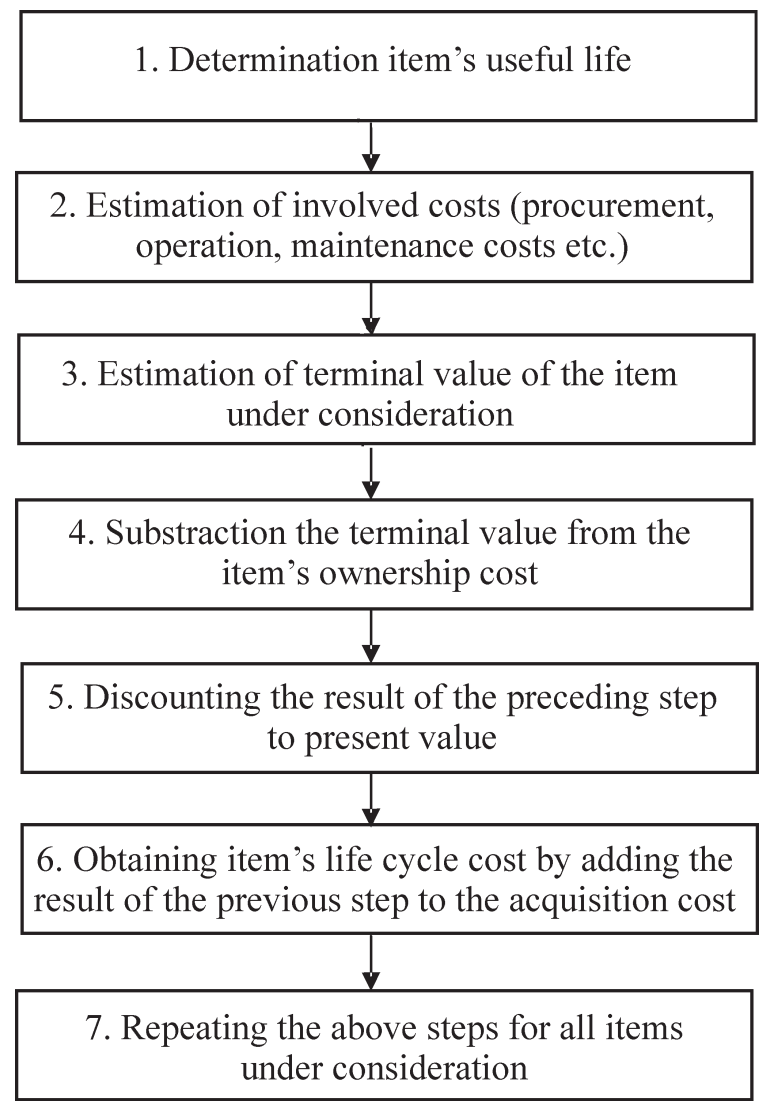

Fig 3. Life cycle costing steps 
system engineering, operations research, data analysis and collection, manufacturing methods and developing specifications. One of the main mistakes here is to create this group under the head from financial department, because usually he has no necessary background in reliability engineering \& quality control and system engineering. In order to command respect for LCC program he should be high enough on the organizational ladder with necessary authority. So, the main condition for successful LCC analysis is corresponding available manpower. In present time only in minority of companies there are resources to organize required high-level research work. In many companies there is nobody that capable even to recognize the problem existence. Hence, in many cases LCC is not performing at all or performing formally. For such companies it may be recommended to order LCC analysis from other company (consulting) that has necessary experience in this field.

A crucial factor for the successful LCC analysis is the attitude and the thinking philosophy of top level management toward reliability [1]. Without the support of the top management, reliability and maintainability programs and Life Cycle Cost analysis will not be effective. If the top level management's positive and effective attitude is generated, then appropriate reliability and maintainability programs can be successful. Such attitude can be created only on the base of corresponding education in the field of reliability engineering. In present time in Israel there are almost no engineers that have background in the field of reliability engineering. There are no corresponding courses in reliability engineering for students in engineering departments (mechanical engineering, electrical engineering, computer science) and the students didn't listen about reliability. Only in Israel Institute of Technology there is engineering specialization Quality Control and Reliability and small courses about mathematical reliability theory are presented in some Universities only for mathematicians and statisticians. Students from economical departments also know nothing about reliability (and graduates from these departments are in the top level management in many companies). Based on such education we cannot hope to have "positive attitude and thinking philosophy of top level management toward reliability" even in the future.

\section{Conclusions}

The reliability associated costs are the main part of total life cycle cost for any repairable system. In the paper management problem of life cycle costing in industry were considered. Skill requirements to associated professionals were determined. It was shown that in majority of companies there is no corresponding manpower to perform effective life cycle cost analysis. Because of absence of reliability education necessity and effectiveness of life cycle cost analysis often are not recognized or the analysis performed formally and incorrectly. Management and education are keys to making the life cycle costing efforts worthwhile.

\section{References}

[1] Dhillon, B. S. Design Reliability. Fundamentals and Applications. London, NY, Washington, D.C.: CRC Press, 2000.

[2] Ryan, W. Procurement views of life cycle costing. In: Proc. Annual Symposium Reliability, 1978, p. 164-168.

[3] Garškienè, A.; Garškaite, K. The Contents of Anticrisis Management: The Essence, Aims and Means. Business: Theory and Practice. Vilnius: Technika, 2005, Vol 6, No 1, p. 44-55.

[4] Logistic Management Institute (LMI). Life Cycle Costing in Equipment Procurement, Report No. LMI Task 4C-5, LMI, Washington, D.C., 1965. 